\title{
Eliminating Mother-to-Child Transmission of Syphilis: Chinese Practice before and during COVID-19 Pandemics
}

\author{
Fangzhi Du', Ruili Zhang ${ }^{2 *}$, Qianqiu Wang ${ }^{1 *}$ \\ ${ }^{1}$ Institute of Dermatology, Chinese Academy of Medical Sciences \& Peking Union Medical College, Nation- \\ al Center for STD Control, China Centers for Disease Control and Prevention, Nanjing 210042, China \\ ${ }^{2}$ Department of Dermatology, the Second Affiliated Hospital of Nanjing Medical University, Nanjing 210003 , \\ China
}

\begin{abstract}
Mother-to-child transmission (MTCT) of syphilis remains a leading cause of stillbirth and death among neonates in many developing countries. In 2007, World Health Orgernization launched the global elimination of MTCT (EMTCT) of syphilis. Given the high burden of congenital syphilis, China subsequently released the specific national EMTCT policies and programs to reduce MTCT of syphilis. The congenital syphilis incidence rate per 100,000 live births in China has markedly decreased from 69.9 in 2013 to 11.9 in 2019. However, due to the global pandemic of COVID-19, the current measures for eliminating MTCT of syphilis are greatly challenged. In this article, we summarize the strategies and measures for the EMTCT of syphilis in China in the past 20 years, the remarkable achievements by the policy support under the leadership of the government. In the context of COVID-19 pandemics, strengthening emergency response to the regional outbreaks of COVID-19, adopting safe, rapid, early and high-quality clinical care for $100 \%$ of pregnant women to receive prenatal syphilis testing services, ensuring the availability of Benzathine penicillin for the treatment, and strengthening the closed-loop management of pregnant women and newborns infected with syphilis are the key measures to determine the effectiveness of MTCT for syphilis. Lessons from China may be valuable for other countries that are planning to eliminate MTCT of syphilis.
\end{abstract}

Key words: mother-to-child transmission; syphilis; COVID-19; China

\section{INTRODUCTION}

The adverse outcomes of pregnant women with syphilis present as stillbirth, early fetal death, low birth weight, preterm delivery, neonatal death, infection or disease in newborns ${ }^{[1,2]}$. In 2016, the World Health Organization (WHO) estimated that annually, about 930,000 pregnant women suffer from active syphilis worldwide, resulting in approximately 350,000 adverse birth outcomes, over half of which are neonatal death and stillbirth ${ }^{[3]}$. Mother-to-child transmission (MTCT) of syphilis, commonly called as "congenital syphilis", remains a leading cause of stillbirth and death of neonates in many developing countries. Studies have demonstrated that, unlike adult acquired syphilis, congenital syphilis can be prevented by screening and treatment of infected mother. In light of the devastating consequences of congenital syphilis, WHO launched the global elimination of MTCT (EMTCT) of syphilis in $2008^{[4]}$. The plan aims to reach the goal that keeping congenital syphilis rate not higher than 50 cases per 100,000 live births through screening of all pregnant women, delivering treatment for all positive cases and their partners, as well as establishing strong surveillance and monitoring systems to sustain eradication or elimination. As Maldives achieved validation for EMTCT of HIV and syphilis in July 2019, a total of 11 countries or regions have achieved validation for EMTCT of HIV

Received March 24, 2021; accepted October 22, 2021; published online February 28, 2022.

*Correspondence to author Qianqiu Wang, wangqianqiunj@126.com; Ruili Zhang, reallyvictor@126.com. 
and/or syphilis ${ }^{[5]}$. Evidences from these countries or regions are of great help to countries in which syphilis is preventable with basic public health activities. However, it remains difficult to eliminate MTCT for many countries worldwide, particularly countries with high burden of maternal syphilis or with high infection rate of syphilis among high-risk populations.

China is one of the countries with high disease burden of syphilis. The number of congenital syphilis cases in China has increased from 468 in 2000 to 10,032 in 2013, the corresponding incidence increased from 2.6 per 100,000 live births in 2000 to 69.9 in 2013, which was nearly 26 -fold higher ${ }^{[6]}$. Facing such a high burden of congenital syphilis, China released national policies and programmes specifically on EMTCT of syphilis. In 2016, it was reported that the congenital syphilis cases in China was 29.8 per 100,000 live births, the population-level antenatal care coverage reached $99 \%$, and HIV and/or syphilis testing cover $99 \%$ of pregnant women ${ }^{[7]}$, which well met the WHO standard for elimination. Based on these achievements, the Ministry of Health ( $\mathrm{MOH}$ ) of People's Republic of China, currently renamed as the National Health Commission of People's Republic of China, launched a project to further eliminate MTCT of syphilis in 2016. At the end of 2019, the reported case rate of congenital syphilis decreased to 11.87 per 100,000 live births ${ }^{[8]}$.

\section{POLICIES AND MEASURES FOR ELIMINATING MTCT IN CHINA}

The $\mathrm{MOH}$ of China launched a pilot project on the prevention of MTCT (PMTCT) in eight counties (cities, districts) of five provinces (regions) in $2002^{[9]}$. In the next year, $\mathrm{MOH}$ issued the National Working Guidelines to Prevent Mother-to-Child Transmission of HIV ${ }^{[9]}$. In 2006, the provision of PMTCT of HIV services was ratified by the AIDS Prevention and Control Regulations, which was announced by the State Council of the People's Republic of China. Subsequently, the health care services were initially provided to all pregnant women with HIV/syphilis/hepatitis B who attended the national sentinel sites ${ }^{[10]}$. Based on the experiences from PMTCT of HIV program, as well as the high burden of maternal syphilis, the $\mathrm{MOH}$ issued the China 2010-2020 Plan for Syphilis Control and Prevention in June $2010^{[11]}$. This plan set an overall target to reduce the incidence of MTCT of syphilis through dual control, which included keeping MTCT of HIV below 15 per 100,000 live births by 2020 , setting several stepwise but ambitious benchmarks for antenatal syphilis screening coverage (80\% by 2015 and $90 \%$ by 2020) and intervention uptake rates ( $90 \%$ by 2015 and $95 \%$ by 2020) among infected mothers and their infants. In 2011, the $\mathrm{MOH}$ further issued a national policy specifically aiming at integrating preventive measures for MTCT of HIV, syphilis and hepatitis $B$, which was implemented as the core strategies for syphilis control in China in the following years $^{[12]}$. Since 2015, the screening of antenatal HIV/ syphilis/hepatitis B and the treatment of HIV/syphilis have covered all pregnant women and their infants throughout the country.

In China, service network of women and children's health (WCH) has been gradually formed, which is composed of general hospitals, $\mathrm{WCH}$ institutions, and community-based healthcare services at multiple levels, e.g., province, district, county, township, and village. At the end of 2018, there were 3,080 WCH institutions, 807 maternity hospitals, and 129 children's hospitals nationwide, playing a core role in EMTCT of $\mathrm{HIV}$ and syphilis ${ }^{[9]}$. Health professionals from the $\mathrm{WCH}$ services network in China provide specialized all-round preventive and curative care. These services include premarital health care, prenatal and postnatal care, reproductive healthcare, neonatal care, infants care, and preschool children care ${ }^{[11]}$. Referral system for syphilis has been established to ensure all people with positive test of syphilis could timely be diagnosed and receive treatment. Even in remote districts, antenatal care and treatment are accessible to mothers and infants with syphilis. To ensure the quality of the care services, training courses are routinely provided to professionals; meanwhile, laboratory testing systems and processes are routinely supervised to ensure the accuracy and reliability of tests.

In 2004, China established the surveillance and early warning systems for infectious diseases, including the National Notifiable Infectious Disease Surveillance System, the Public Health Emergency Event Surveillance System, and the China Infectious Disease Automated-alert and Response System ${ }^{[13]}$. The surveillance systems cover all types of health facilities at all levels, including health administrative authorities, hospitals, centers of disease control and prevention (CDCs), health facilities at national, provincial, prefectural/city, and county/district levels, rural community health centers, township health centers, and even village clinics. As one of 39 notifiable infectious diseases, syphilis is 
reported and surveilled through this system. Besides, a monitoring system of MTCT has also be established to collect and analyze data from service network of WCH. In addition, China CDC has set up 1,883 national sentinel sites to carry out routine surveys of HIV and syphilis in high-risk populations, such as homosexuals, female sex workers, injection drug users, as well as pregnant women. Data from these surveys greatly contribute to monitoring the incidence of MTCT of HIV and syphilis among these populations.

In China, laws to promote and protect human rights of women and children, health rights, and gender equality have been enacted, such as the Law on Maternal and Child Health Care, and Provisions on Female Workers' Protection. To better support implementing these laws, the $\mathrm{MOH}$ has issued a series of policies ${ }^{[9]}$, including Regulations on Technology Licensing and Personnel Qualification in Women and Children's Health, Regulations on Prenatal Diagnostic Technology Management, Neonatal Screening Management Regulation, and Maternal and Child Health Institution Management Regulations. These policies respect the rights of women and children in accessing information and resources, emphasis their social, spiritual and moral wellbeing, promote their physical and mental health, provide preventive healthcare services, sex education, education on family planning, and protect them from violence. Besides, there are laws and regulations specifically issued for protecting human rights of people living with HIV/syphilis, such as Infectious Disease Prevention Law of People's Republic of China, Regulation on Prevention and Treatment of Sexually Transmitted Diseases, and Regulation on Prevention and Treatment of AIDS. People living with HIV/syphilis have access to the treatment, prevention, and associated healthcare services, and are protected from stigma and discrimination. In addition, some social groups and non-governmental organizations in China are committed to work on human rights of people living with HIV/syphilis.

\section{PROBLEMS AND DIFFICULTIES OF EMTCT OF SYPHILIS IN CHINA}

While China has made significant achievements in EMTCT of syphilis, there remains a gap to full success of EMTCT of syphilis.

Firstly, despite the high coverage of antenatal care and syphilis testing in pregnant Chinese women, it is estimated that only $80 \%$ of pregnant women with positive test of syphilis receive proper treatment, and only $53 \%$ complete recommended treatment for syphilis during pregnancy ${ }^{[14]}$. The main reason is that many pregnant women start to receive antenatal care in the last trimester, which is too late to receive two-course anti-syphilis therapy, because the time interval of twocourse treatment is at least four weeks. In response, the current Chinese Syphilis Treatment Guidelines recommend one-course treatment with three injections of benzathine penicillin $\mathrm{G}$ to infected pregnant women, disregarding their syphilis stages, with exception of neurosyphilis or cardiovascular syphilis ${ }^{[15]}$. However, pregnant women of floating population who are not registered in local household registration system and people in remote area of China do not have full access to these care services, which needs to be improved in future.

Secondly, China maintains large number of newly reported syphilis case each year; for instance, a total of 587,404 new cases were reported in $2019^{[16]}$. The high prevalence of syphilis, particularly among the high-risk populations, leads to a high incidence of maternal syphilis, and hence a high incidence of congenital syphilis ${ }^{[17]}$. For EMTCT of syphilis, effective control in high-risk population is as the same important as in pregnant women.

Thirdly, there are no legal frameworks and actions in China by law to govern stigmatization and discrimination against women with syphilis and their families. Meanwhile, unlike HIV having gained good awareness among the public, syphilis remains silent in China. The fear of stigma prevents people from seeking for test and treatment, which aggravates the spread of the disease as a "stealth" in population. Intensive efforts are needed urgently to reduce the stigma and discrimination against the infected in public. For instance, general campaigns raise more syphilis-related awareness, celebrities disseminate proper information and messages about syphilis, women living with syphilis claim their human right, and senior political figures engage in syphilis-related activities, etc.

\section{IMPACT OF COVID-19 ON MTCT OF SYPHILIS IN CHINA}

On March 11, 2020, WHO declared coronavirus disease 2019 (COVID-19) a global pandemic. According to the official website of WHO updated on February 
23, 2022, number of global infections of COVID-19 exceeded 420 million $^{[18]}$. With the rapid spread of COVID-19 around the world, the global healthcare sector faces huge challenges on prevention and control of sexually transmitted diseases. A few months after the outbreak of COVID-19, many countries enact strict prevention measures, such as social distancing, stayat-home order, banning entertainment activities, closing nonessential businesses, etc ${ }^{[19-22]}$. Meantime, many health care clinics either close or limit in-person visits to symptomatic cases, and accesses to STD intervention services are limited as well. Screenings and hospital visits reduced, treatment and follow-up services postponed, which results in a significant decrease in the incidence of new reported syphilis ${ }^{[23,24]}$.

In the early months after the outbreak of COVID-19 in China, the medical resources were resolutely assigned to the management of COVID-19 infections with priority in severely affected areas, such as Wuhan. With the shutdown of hospitals, redeployment of clinicians and ward beds resources, the STD healthcare for pregnant women and the follow-up services for newborns were inevitably postponed. Meanwhile, as COVID-19 epidemics were predicted to be long-lasting, EMTCT plans for syphilis were delayed due to diversion of medical resources. Secondly, transportation and logistics were affected by the epidemics, which causes shortages of benzathine penicillin in epidemic areas, and thus postponed treatment of syphilis infected pregnant women. The epidemics of COVID-19 have been reported to affect the availableness and timeliness of sexually transmitted disease (STD) healthcare for syphilis patients and their sexual partners ${ }^{[23]}$. On the other hand, novel coronavirus infection has been reported causing transient immunodeficiency, with potentially harmful immunological and clinical consequences $^{[25]}$, which may change the course of syphilis and affect the therapeutic effect.

\section{STRATEGIES ON EMTCT OF SYPHILIS IN CHINA DURING EPIDEMIC OF COVID-19}

In view of long-lasting COVID-19 pandemic, it is necessary to make an emergency preparedness to ensure timely response regarding EMTCT of syphilis when regional outbreak occurs. The measures may include: 1) $\mathrm{WCH}$ institutions provide visiting service of syphilis counselling and testing to ensure timely prenatal screening for isolated pregnant women; otherwise, to set up dedicate clinics for prenatal counseling and testing, and provide transportation to transfer pregnant women to the clinics ; 2) WCH institutions reserve separate wards for the treatment to syphilis-infected pregnant women; 3) local health administration departments ensure the availability of benzathine penicillin supply.

Secondly, in area that telemedicine is well developed, and self-testing reagents for syphilis are applicable, local WCH institutions can guide pregnant women to use self-test kit at home and interpret test results themselves, and provide online counseling services. The COVID-19 pandemic might be an excellent opportunity for care providers to assess the acceptability of telemedicine among syphilis patients, examine its impact on the quality of health care, and establish models for patient-centered health services, particularly in hard-to-access populations.

Thirdly, establishing surveillance network for emerging threats to MTCT of syphilis can leverage existing data sources, quickly gather data, and facilities guidance on clinical practice. These data help to reduce exposure risks and adverse outcomes for pregnant women with syphilis and their babies, and provide guidance to public health action. In 2019, the US established the Surveillance for Emerging Threats to Mothers and Babies Network (SET-NET), which provides a population-based approach to longitudinal maternal and infant surveillance, and has demonstrated rapid adaptation to the COVID-19 epidemics, as well as the flexibility and utility for new emerging threats ${ }^{[26]}$.

In addition, follow-up of infants born to syphilis infected mother is always a great challenge, and COVID-19 epidemics may make the situation worse. Therefore, management of infants born to syphilis infected mother should be undertake by receiving hospital at a one-on-one base and followed up regularly to achieve a closed-loop management of diagnosis and treatment. Moreover, pregnant women also need to strengthen protection to reduce the infection risk of COVID-19.

\section{SUMMARY}

The remarkable achievements in EMTCT of syphilis in China illustrate the importance of strong leadership and policy support of the government, as well as the crucial role of a high coverage of antenatal care and a well-organized monitoring and surveillance 
system. Under the COVID-19 pandemics, more intensify efforts are continually urgent to ensure the full accessibility of prenatal syphilis screening services to all pregnant women, and to promote treatment and follow-up of seropositive pregnant women and exposed infants. In addition, telemedicine and surveillance network for emerging threats to MTCT of syphilis can be helpful for the above challenges. Collaborations among policy makers, celebrities, media, and syphilitic patients are also needed to promote the public awareness of syphilis. We hope Chinese practice in MTCT may be valuable for other countries that are planning to eliminate MTCT of syphilis.

\section{Conflict of interests}

None.

\section{Funding}

National Natural Science Foundation of China (81772209 and 81601804).

\section{Author contributions}

$Q Q W$ and $R L Z$ build the conception, critically reviewed the manuscript. QQ W, RL Z and FZ D prepared, wrote, or revised the manuscript. All authors approved the final version of the article.

\section{REFERENCES}

1. Newman L, Kamb M, Hawkes S, et al. Global estimates of syphilis in pregnancy and associated adverse outcomes: analysis of multinational antenatal surveillance data. PLoS Med 2013; 10(2): e1001396. doi: 10.1371/journal.pmed.1001396.

2. Zhang $X, Y u$ Y, Yang $H$, et al. Surveillance of maternal syphilis in China: pregnancy outcomes and determinants of congenital syphilis. Med Sci Monit 2018; 24:7727-35. doi: 10.12659/ MSM. 910216.

3. Wijesooriya NS, Rochat RW, Kamb ML, et al. Global burden of maternal land congenital syphilis in 2008 and 2012: a health systems modelling study. Lancet Glob Health 2016; 4(8): e525-33. doi: 10.1016/S2214-109X(16)30135-8.

4. World Health Organization. The global elimination of congenital syphilis: rationale and strategy for action. Available from https://www.who.int/publications/i/item/the-global-elimination-of-congenital-syphilis-rationale-and-strategy-for-action. Accessed March 10, 2021.

5. World Health Organization. Global Sexually Transmitted Infections Programme. Mother-to-child transmission of syphilis. Available from https://www.who.int/reproductivehealth/congenital-syphilis/en/. Accessed March 10, 2021.

6. Zhang XY, Li M, Feng YB, et al. Meta-analysis of effect of pre- vention of mother to child transmission of HIV during 20112014 in China. Chin J AIDS STD 2015; 21(4): 275-9. doi: 10.13419/j.cnki.aids.2015.04.06.

7. Wu X, Feng T, Yu W. Prevention of mother-to-child transmission of syphilis: technical measures and effectiveness. Electr J Emerging Infect Dis 2019; 4(4):204-8. doi: 10.19871/j.cnki. xfcrbzz.2019.04.004.

8. Yue $X L$, Gong $X D$, Li J, et al. Trends and epidemiologic features of syphilis in China, 2014-2019. Chin J Dermatol 2021; 54(7): 47-51. doi: 10.35541/cjd.20210098.

9. Ministry of Health, People's Republic of China. Report on women and children's health development in China (2011). Available from http://www.gov.cn/gzdt/att/att/ site1/20110921/001e3741a4740fe3bdbf02.pdf. Accessed March 10, 2021.

10. Wu Z, Sullivan SG, Wang $Y$, et al. Evolution of China's response to HIV/AIDS. Lancet 2007; 369 (9562): 679-90. doi: 10.1016/S0140-6736(07)60315-8.

11. Embassy of the People's Republic of China in the United State of America. The State Council Information Office of the People's Republic of China. Government white papers: medical and health services in China. Available from http://www. china-embassy.org/eng/zt/bps/t1001641.htm. Released December 29, 2012; accessed March 10, 2021.

12. Chen XS, Jiang TT, Yin YP, et al. Circulating microRNAs as potential biomarkers in the diagnosis of neurosyphilis. Int J Dermatol Venereol 2020; 3(4):193-7. doi: 10.1097/ JD9.0000000000000134.

13. The State Council Information Office of the People's Republic of China. Medical and health services in China: white paper. Available from http://www.china-embassy.org/eng/zt/bps/ t1001641.htm. Accessed February 15, 2021.

14. Gong T, Shao Y, Liu J, et al. Treatment evaluation to improve preventing mother to child transmission among women with syphilis. Sci Rep 2019; 9(1):19547. doi: 10.1038/s41598019-56095-6.

15. National Center for STD Control, China Centers for Disease Control and Prevention; Venereology Group, Chinese Society of Dermatology; Subcommittee on Venereology, China Dermatologist Association. Guidelines for the diagnosis and treatment of syphilis, gonorrhea, and genital chlamydial infection. Chin J Dermatol 2020; 53(3):168-79. Chinese. doi: 10.35541/cjd.20190808.

16. Bureau of Disease Prevention and Control, National Health Commission of the People's Republic of China. National overview of statutory infectious disease outbreaks in 2019. Available from http://www.nhc.gov.cn/jkj/s3578/202004/ b1519e1bc1a944fc8ec176db600f68d1.shtml. Released April 20, 2020. Accessed February 15, 2021.

17. Chen XS. Turning off the tap: sustaining elimination of congenital syphilis through the programme targeting high-risk groups. J Glob Health 2019; 9(2): 020312. doi: 10.7189/ jogh.09.020312.

18. World Hearlth Orgernization. Coronavirus disease (COVID-19) pandemic. Available from https://www.who.int/emergencies/ 
diseases/novel-coronavirus-2019. Accessed February 25, 2022.

19. Moreland A, Herlihy C, Tynan MA, et al. Timing of state and territorial COVID-19 stay-at-home orders and changes in population movement: United States, March 1 - May 31, 2020. MMWR Morb Mortal Wkly Rep 2020; 69(35): 1198-203. doi: 10.15585/mmwr.mm6935a2.

20. Czeisler M, Tynan MA, Howard ME, et al. Public attitudes, behaviors, and beliefs related to COVID-19, stay-at-home orders, nonessential business closures, and public health guidance-United States, New York City, and Los Angeles, May 5-12, 2020. MMWR Morb Mortal Wkly Rep 2020; 69(24): 751-8. doi: 10.15585/mmwr.mm6924e1.

21. Centers for Disease Control and Prevention. Guidance for businesses and employers responding to coronavirus disease 2019 (COVID-19). Available from https://www.cdc.gov/coronavirus/2019-ncov/community/guidance-business-response. html. Accessed September 20, 2021.

22. Executive Office of the President. Declaring a National Emergency Concerning the Novel Coronavirus Disease (COVID-19) Outbreak. Daily J US Govern 2020; 85(53): 15337-8. Available from https://www.federalregister. gov/documents/2020/03/18/2020-05794/declaring-a-national-emergency-concerning-the-novel-coronavirus-disease-covid-19-outbreak. Released March 18, 2020. Accessed September 20, 2021.

23. Pagaoa M, Grey J, Torrone E, et al. Trends in nationally notifiable sexually transmitted disease case reports during the US COVID-19 pandemic, January to December 2020. Sex Transm Dis 2021; 48(10):798-804. doi: $10.1097 /$ OLQ.0000000000001506.

24. Sentís A, Prats-Uribe A, López-Corbeto $E$, et al. The impact of the COVID-19 pandemic on Sexually Transmitted Infections surveillance data: incidence drop or artefact? BMC Public Health 2021 ; 21(1):1637. doi: 10.1186/s12889-02111630-x.

25. Härter G, Spinner CD, Roider J, et al. COVID-19 in people living with human immunodeficiency virus: a case series of 33 patients. Infection $2020 ; 48(5): 681-6$. doi: 10.1007/s15010020-01438-z.

26. Woodworth KR, Reynolds MR, Burkel V, et al. A preparedness model for mother-baby linked longitudinal surveillance for emerging threats. Matern Child Health J 2021; 25(2):198206. doi: 10.1007/s10995-020-03106-y. 
观点

\title{
消除梅毒母婴传播：中国在 COVID-19 大流行前和流行期间 的实践经验
}

\author{
杜方智 ${ }^{1}$, 张瑞丽 ${ }^{2 *}$, 王千秋 ${ }^{1 *}$ \\ ${ }^{1}$ 中国疾病预防控制中心性病预防控制中心，中国医学科学院北京协和医学院 \\ 皮肤病学研究所, 南京 210042 , 中国 \\ 2 南京医科大学第二附属医院皮肤科, 南京 210003 , 中国
}

\begin{abstract}
摘要
在许多发展中国家，梅毒的母婴传播（mother-to-child transmission, MTCT) 仍然是新生儿死产和死亡的主 要原因。2007 年, 世界卫生组织启动了全球消除梅毒 MTCT 的计划。鉴于先天性梅毒的高疾病负担, 中国随后发 布了国家梅毒 EMTCT 政策和方案，以减少梅毒的 MTCT。中国的先天性梅毒报告发病率由 2013 年的 69.9 例 / 10 万活产下降到 2019 年的 12.0 例 / 10 万活产。当前在新型冠状病毒肺炎 (COVID-19) 全球大流行期间, 消除梅毒 MTCT 领域的工作进展受到拖延, 使消除和终止梅毒 MTCT 的计划面临巨大挑战。本文总结了近 20 年来中国在 消除梅毒 MTCT 的策略和措施, 指出在国家卫生政策的支持和政府的坚强领导下, 中国消除梅毒 MTCT 取得了显 著的成就。在 COVID-19 大流行期间, 加强对区域性暴发的 COVID-19 疫情的应急响应, 采用安全、快速、早期 和高质量的临床护理, 确保 $100 \%$ 的孕妇获得产前梅毒检测服务, 确保治疗用苠星青霉素的药物供给, 加强对感 染梅毒孕妇和新生儿的闭环管理, 是决定梅毒 MTCT 效果的关键措施。中国的经验教训可能对其他正在计划消除 梅毒 MTCT 的国家有借鉴价值。
\end{abstract}

关键词: 母婴阻断; 梅毒; 新型冠状病毒肺炎; 中国

基金: 中国医学科学院联合创新团队项目（2016-I2M-3021）; 国家自然科学基金项目（81772209和 81601804）; 南京市国家级临床医学中心培育计划项目（2019060001）

通讯作者：王千秋 wangqianqiuj@126.com 